\title{
CRÍTICA DA TIPOLOGIA DA VIOLÊNCIA DE GÊNERO
}

\author{
http://dx.doi.org/10.21527/2176-6622.2019.51.6-20
}

Recebido em: 1ㅇ/3/2019

Aceito em: 26/5/2019

\section{André Leonardo Copetti Santos}

Doutorado em Direito pela Unisinos (2004). Professor e pesquisador do Programa de Pós-Graduação em Direito da Unijuí. andre.co.petti@hotmail.com

\section{Doglas Cesar Lucas}

Doutorado em Direito pela Unisinos e Pós-Doutorado em Direito pela Università Degli Studi di Roma Tre. Professor dos Cursos de Graduação, Mestrado e Doutorado em Direito da Universidade Regional do Noroeste do Estado do Rio Grande do Sul - Unijuí/RS e do Curso de Graduação em Direito da Faculdade CNEC Santo Ângelo. Professor colaborador do Mestrado e Doutorado em Direito da URI - Santo Ângelo. Editor-Chefe da Revista Direitos Humanos e Democracia. Avaliador Inep/MEC. Advogado. doglasl@unijui.edu.br

\section{Evelyne Freistedt Copetti Santos}

Mestrado em Direitos Especiais (vinculado à Linha de pesquisa Direito e Multiculturalismo) pelo Programa de Pós-Graduação Stricto Sensu - Mestrado em Direito da Universidade Regional Integrada do Alto Uruguai e das Missões, Campus Santo Ângelo/RS (2015). Graduação em Direito pela Universidade do Vale do Rio dos Sinos - Unisinos (2006). Avaliadora e revisora da Revista Científica Direitos Culturais. Advogada. evecopetti@hotmail.com

\section{RESUMO}

A violência tem sido uma das manifestações constantes da humanidade baseada em várias premissas, entre elas, as relações de poder. No caso das mulheres, a cultura patriarcal tem demarcado a maior parte de sua existência, atuando como um agente violento, opressor e limitador da boa convivência humana. Mediante um estudo hipotético dedutivo, fundamentado nas ideias estruturantes da violência, o presente estudo busca analisar, num primeiro momento, uma tipologia geral da violência, para, posteriormente, abordar esta tipologia referentemente ao universo das relações de gênero, e, ao final, abordar a tipologia que está positivada institucionalmente na Política Nacional de enfrentamento à Violência contra as Mulheres no Brasil. O estudo em voga denota que a cultura patriarcal é uma construção social que se utiliza das mais diversas formas de violência e tem se estruturado nas relações sociais e nos poderes constituídos. Fissuras nessa cultura, porém, foram e seguem sendo exploradas pelos movimentos sociais, especialmente os feministas, que têm contribuído decisivamente para o câmbio desses valores, empoderando mulheres e homens por intermédio do Direito.

Palavras-chave: Violência. Violência de gênero. Tipologia. Cultura patriarcal. Institucionalização. Política nacional.

\section{CRITICISM OF THE TYPOLOGY OF GENDER VIOLENCE}

\section{ABSTRACT}

Violence has been one of the constant manifestations of humanity, based on several premises, among them, the relations of power. In the case of women, the patriarchal culture has demarcated most of its existence, acting as a violent, oppressive and limiting agent of good human coexistence. Through on a hypothetical deductive study, based on the structuring ideas of violence, the present study seeks to analyze, in a first moment, a general typology of violence, to later approach this typology referring to the universe of gender relations, and, in the end, to approach the typology that is positively institutionalized in the National Policy to combat Violence against Women in Brazil. The study in vogue shows that patriarchal culture is a social construction that uses the most diverse forms of violence and has been structured in social relations and constituted powers. However, fissures in this culture have been and continue to be exploited by social movements, especially feminists, who have contributed decisively to the change of these values, empowering women and men through law.

Keywords: Violence. Gender violence. Typology. Patriarchal culture. Institutionalization. National policy.

\section{SUMÁRIO:}

1 Introdução. 2 Sobre as tipologias da violência. 2.10 embate objetivismo x subjetivismo e suas repercussões na representação das tipologias da violência. 3 Gênero e violência como critérios de marcação dos fenômenos de violência. 4 A tipologia da violência na política nacional de enfrentamento à violência contra as mulheres no Brasil. 5 Considerações finais. $O$ grande desafio em termos de violência de gênero: o enfrentamento do poder simbólico e da coerção das estruturas sociais e suas condições determinantes da violência. 


\section{INTRODUÇÃO}

A complexidade e a dinâmica altamente veloz do mundo nos colocaram imensos desafios de compreensão de uma série infindável de fenômenos que se potencializaram com o exponencial aumento das inter-relações entre sistemas sociais e entre as próprias pessoas individualizadamente, situações que se tornaram possíveis no estágio em que estão em razão de uma mudança radical nas tecnologias. A violência é um destes fenômenos que, ainda que seja tão velho como a humanidade, têm reclamado novas bases conceituais e novas investigações que permitam uma melhor apreensão de suas versões contemporâneas.

Diariamente nos deparamos com situações que podem ser classificadas como border lines entre violência e não violência, aquelas que estão situadas entre manifestações consagradas e injustificáveis de violência, como a violência física dos homicídios ou das lesões, como a violência das guerras ou de atos terroristas, e atos e condutas que são a negação completa da violência. O capitalismo é um modo racional de produção da riqueza ou um sistema de exploração no qual impera uma violência sistêmica praticamente imperceptível ou negada especialmente por aqueles que se beneficiam do sistema? Os regimes comunistas necessitaram fazer uso da violência para corrigir uma violência ainda maior do capitalismo, portanto um uso justificável e despido do principal elemento resultante da violência - a dor - ou, de outra forma, foram regimes nos quais a violência era uma condição intrínseca às próprias necessidades organizacionais e de sobrevivência do sistema político? Dentre essas manifestações que, muitas vezes, são malcompreendidas e interpretadas, ou têm sido naturalizadas por sistemas comunicacionais intencionalmente dirigidos à dominação, está a violência de gênero, em muitas de suas formas, na zona limite de violência e não violência, apesar de se constituírem como absoluta de manifestação de violência. As próprias tentativas de neutralização da questão de gênero não seria, por si só, uma violência?

Naturalizada e obnubilada por séculos pela dominação patriarcal, a violência de gênero, por força das atuações dos movimentos sociais nas últimas cinco ou seis décadas, passou a ser profundamente questionada, resistida, teorizada e enfrentada, tendo sido, na contemporaneidade, objeto de uma série de institucionalizações garantistas, no âmbito constitucional e infraconstitucional, que têm proporcionado um conjunto de ações públicas que, se ainda não chegaram a um ponto ótimo da sua erradicação, têm, pelo menos, indicado que a sociedade e o Estado despertaram para a existência desse nefasto fenômeno social.

Se um dos piores resultados da violência é a dor humana, as violências são, também, traduções dos medos da "dor" na sua condição física (medo das doenças), medo do erro de inteligência (formas de pensar, ignorância, incertezas), medo do desconhecido em sua espiritualidade (castigo de Deus e/ou invasão do Diabo), medo do outro, em sua lógica mental (a presença do outro diferente e estranho que não fala ou dialoga), medo do desprezo que vem da nossa dimensão afetiva (a atração amorosa ou paixão - sexualidade, o abandono familiar), medo da miséria e da pobreza que vem com a condição econômica (renda para a dignidade de alimentar-se, de ter saúde, para morar, ter trabalho, educar-se...), etc. Cercado destes medos, os atos de esperanças tornam-se residuais e isolados e sem efeitos para consertar, refazer ou reconstruir. Que medo move, todavia, os varões ou os sistemas patriarcais de dominação a infligirem tantas dores, por tanto tempo, a mulheres, gays, lésbicas, bissexuais, travestis e outros tipos de pessoas cuja sexualidade não se enquadra em padrões majoritários heterossexuais?

A proposta do presente trabalho radica-se numa intencionalidade de estruturar uma crítica da violência de gênero para melhor compreender esse fenômeno, de modo a podermos, a partir disto, esboçar novas tecnologias políticas e jurídicas de proteção a esses grupos minoritários. A ideia de minoria que nos auxilia não é quantitativa. As minorias, como propõe Deleuze (1992, p. 218), não se distinguem pelo número. Uma minoria pode ser mais numerosa que a maioria. $O$ que define a maioria é um modelo ao qual é preciso estar conforme: por exemplo, o europeu médio adulto heterossexual habitante das cidades. Ao passo que uma minoria não tem modelo, é um devir, um processo. Quando a minoria cria para si modelos, é porque quer se tornar majoritária, e sem dúvida isso é inevitável para sua sobrevivência ou salvação (por exemplo, ter um Estado, ser reconhecido, impor seus direitos). 
A alternativa metodológica utilizada para o desenvolvimento da pesquisa foi a hipotética dedutiva, uma vez que o percurso investigativo inicia com uma abordagem genérica da violência, passando por uma especificação conceitual da violência de gênero, até chegarmos com esse arcabouço conceitual genérico e aplicarmo-lo à Política Nacional de enfrentamento à Violência contra as Mulheres no Brasil, a fim de verificarmos que tipologia foi adotada neste plano estatal de enfrentamento deste problema.

\title{
2 SOBRE AS TIPOLOGIAS DA VIOLÊNCIA
}

\begin{abstract}
O Diabo é mulher
O livro Malleus Maleficarum, também chamado O martelo das bruxas, recomendava o mais impiedoso exorcismo contra o demônio que tinha tetas e cabelos compridos.

Dois inquisidores alemães, Heinrich Kramer e Jakob Sprenger, escreveram, por encomenda do papa Inocêncio VIII, esse fundamento jurídico e teológico dos tribunais da Santa Inquisição.

Os autores demonstravam que as bruxas, harém de Satã, representavam as mulheres em estado natural, porque toda bruxaria provém da luxúria carnal, que nas mulheres é insaciável. E advertiam que esses seres de aspecto belo, contato fétido e mortal companhia encantavam os homens e os atraíam, silvos de serpente, caudas de escorpião, para aniquilá-los.

Esse tratado de criminologia aconselhava a submeter a tormento todas as suspeitas de bruxaria. Se confessavam, mereciam o fogo. Se não confessavam, também, porque só uma bruxa, fortalecida pelo amante, o Diabo, nas festas de feiticeiras, conseguia resistir a semelhante suplício sem abrir a boca.

O papa Honório III havia sentenciado:

- As mulheres não devem falar. Seus lábios carregam o estigma de Eva, que foi a perdição dos homens.

Oito séculos mais tarde, a Igreja Católica continua negando-lhes o púlpito.

O mesmo pânico faz com que os fundamentalistas muçulmanos lhes mutilem o sexo e tapem seus rostos.

E o alívio pelo perigo conjurado move os judeus muito ortodoxos a começar o dia sussurrando:

- Obrigado, Senhor, por não me ter feito mulher (GALEANO, 2008, p. 115-117).
\end{abstract}

Pouquíssimas figuras são tão emblemáticas, ao longo da história, como foi a do Diabo. Afinal, quem é essa figura, colorida em múltiplos tons de cinza e negro por Eduardo Galeano? Em primeiro lugar não era, segundo os textos sagrados - a Bíblia -, uma entidade de mil facetas, ou um conjunto de valores negativos, como nos conta o escritor uruguaio, mas personificadamente único; ${ }^{1}$ um anjo chamado Lúcifer que, seduzido narcisisticamente pela própria beleza, entendeu que deveria receber a mesma admiração que Deus e, em razão disso armou uma rebelião com aproximadamente um terço dos anjos que existiam nos céus. ${ }^{2}$ Esta descrição fantástica e sobrenatural do Diabo é própria da tradição judaico-cristã: "Vós tendes por pai ao Diabo, e quereis satisfazer os desejos de vosso Pai; ele foi homicida desde o princípio, e não se firmou na verdade, porque não há verdade nele, quando ele profere mentira, fala do que lhe é próprio, porque é mentiroso e pai da mentira". ${ }^{3} A$ descrição oficial, ou melhor, a primeira versão publicada pela igreja da invenção do Diabo, data de depois do Concílio de Toledo, em 447 d.C., sendo ele solene e burocraticamente descrito e difundido como a encarnação absoluta do mal. Nessas descrições constam a imagem de um ser medonho, muito grande e forte, de aparência escura, com chifres na cabeça, exatamente como o deus-touro Mithra, a quem a igreja queria impedir a adoração. Nasce, com isso, o demônio na cultura cristã, como a mais radical oposição a um projeto de mundo e de bem, cuja personificação plantou o medo nas pessoas que aderissem aos seus cultos, pois o castigo final seria a morte sem direito à vida eterna, seja em qual modalidade fosse (terrena ou espiritual).

\footnotetext{
A versão bíblica do Diabo o revela como uma pessoa real, não apenas o mal no coração de alguém. BíBLIA SAGRADA, Mateus 4: 1-11, 1988, 2a parte, p. 5.

2 BíBLIA SAGRADA, Ezequiel 28: 12-19, 1988, p. 801.

BÍBLIA SAGRADA, João 8: 44, 1988, 1a parte, p. 118.
} 
Com outro olhar, podemos compreender o Diabo de uma forma mais terrena, histórica e estratégica, como uma farsa instrumentalmente criada para funcionar como uma ferramenta de repressão, opressão e imposição de certos valores propagados por indivíduos e grupos ligados a posições privilegiadas dentro de sistemas de dominação. A riqueza da descrição de Galeano reside no fato de condensar algumas associações históricas, escancaradamente dissimuladas, que foram feitas por detentores do poder, entre a figura do Diabo e parcelas de indivíduos submetidas aos caprichos dos poderosos, e, por isso, perseguidos, presos e mortos por estarem associados a uma figura que personificava o mal. O Diabo, nessa perspectiva, expressa manifestamente as separações e segregações, e as violências impostas pelos detentores do poder a minorias por eles indesejadas por dificultarem seus projetos de poder.

A associação de determinadas parcelas da população ao Diabo foi e tem sido uma tentativa de naturalizar e de normalizar processos de violência, como formas de manejo de conflitos que se creem constitutivos das relações sociais. Esta maneira, entretanto, de pensar os conflitos e a eles associar a utilização da violência como forma de solução, carrega consigo uma certa dose de determinismo, quando absolutamente não há determinismo algum, mas somente circunstancialidades e contingências. As distintas sociedades existentes no mundo não carecem da existência de certos conflitos e de determinadas formas de violência em seus processos de constituição. Esses processos são construídos.

No caso da violência de gênero não é diferente. As diferenças biológicas entre homens e mulheres têm justificado as diferenças de gênero masculino e feminino, e, ao se utilizar o recurso biológico, as distinções socioculturais se transformam em imutáveis. As características biológicas sustentam uma distinção cultural arbitrária e histórica como são as categorias de gênero, com sua consequente variabilidade segundo os sistemas socioculturais. Os aspectos biológicos adquirem maior ou menor envergadura segundo as argumentações teóricas, mas nunca deixam de se constituírem no eixo sobre o qual transitam as categorias de gênero. As sociedades matriarcais formam parte mais da mitologia científica do que das evidências etnográficas. Os sistemas socioculturais estruturam-se sobre uma base de supremacia masculina, sociedades patriarcais (MOORE, 1996) ou androcêntricas (ROSALDO, 1978), segundo alguns autores.

\section{O que é preciso destacar em termos de violência, concordando com Rita Segato (2013), é que}

Si pasamos revista a la tipología de la violencia (bélica, institucional, terrorista, crimen organizado, feminicidio, bandas criminales, violencia policial, etc.) todas las conexiones y reclutamientos existentes entre estos niveles de violencia que atraviesan de arriba abajo, todo el continente social hasta los niveles capilares de las relaciones más íntimas giran en espiral a partir de una célula elemental que prolifera ad infinitum: la escena elemental del patriarcado, con su mandato de poder. En cualquiera de estos estratos y modalidades, siempre la exacción de tributo moral o material para la constitución o realimentación del poder, o la disputa por poder - económico, político - forman parte del móvil en esta economía simbólica beligerante e inestable.

Um dos aspectos que tem caracterizado positivamente o processo civilizatório é o contínuo desvelamento das distintas formas de violência. Nesse processo, tanto a academia, pela elaboração de teorias críticas, quanto os movimentos sociais, cujo principal eixo de ação é o reconhecimento de diferenças como elemento central de processos identitários e de reivindicação de redistribuição de bens sociais, têm desempenhado um importantíssimo papel, uma vez que a identificação de diferentes tipos de violência tem permitido ações mais pontuais e eficazes em termos de políticas públicas e institucionalizações normativas. Um exemplo reverso é significativo para ilustrar essa importância no diagnóstico dos diversos tipos de violência. $O$ deficiente diagnóstico das causas da criminalidade no Brasil tem levado à adoção de uma política massiva de encarceramento - chegamos ao terceiro lugar no ranking dos países com maior população carcerária, algo em torno de 727.000 presos (BRASIL, 2016a) -, sem uma correspondente diminuição da ocorrência de crimes em nosso país. Muito pelo contrário, os números têm aumentado ano após ano.

Nesse sentido, adentrarmos na lógica social que se oculta nestes processos de violências, buscando diferenciar os distintos aportes que, desde o plano sociocultural, podemos fazer; é o móvel que orienta essa nossa busca teórica. De uma pluralidade de vozes disciplinares preocupadas pela temática, buscaremos deslindar aqueles aportes que nos permitem compreender de que modo se percebem os processos e/ou atos de violência, e quais são as condições estruturais que facilitam sua ocorrência. Essa base investigativa teórico-especulativa tem a finalidade de aprimorar o máximo possível a diagnose dos tipos de violência e suas respec- 
tivas causas como meio de criação de alternativas de otimização dos processos de tomadas de decisão em termos de quais estratégias políticas e jurídicas são as mais adequadas, dentro de nossa realidade social, para o tratamento do fenômeno da violência de gênero.

Um primeiro passo para deslindarmos a questão da tipologia da violência é a formulação de uma crítica da violência, utilizando aqui o termo em duas acepções a serem trabalhadas conjuntamente: a primeira, no sentido kantiano, significando a delimitação de limites; a segunda, como uma teoria do inconsciente, com a finalidade de trazer à consciência aquilo que não se tem consciência, tal como fez Marx, dirigindo-se ao que está oculto: a religião, a política, as leis, etc. - o todo cultural que "conduz" nossas vidas - os quais disfarçam e transformam um meio econômico de produção artificial em perfeitamente natural, os "mecanismos ocultos da sociedade", um inconsciente econômico que permeia todo o tom crítico de sua obra, como trabalhou Freud em relação à estrutura psíquica dos seres humanos.

Desde essas duas perspectivas críticas, primeiramente é importante demarcar alguns conceitos sobre violência. Benjamin (2011), asseverando que a tarefa de uma crítica da violência pode se circunscrever à apresentação de suas relações com o direito e a justiça, define-a afirmando que "qualquer que seja o modo como atua uma causa, ela só se transforma em violência, no sentido pregnante da palavra, quando interfere em relações éticas. A esfera dessas relações é designada pelos conceitos de direito e justiça" (p. 121). Já para Françoise Heritier (1996), a violência é um fenômeno que se produz nos sujeitos, reflete-se em todos os âmbitos de desempenho social - família, sociedade, Estado - e obedece a fatores culturais, sociais e psicológicos, podendo ser definida como "toda coação de natureza física ou psíquica suscetível de levar ao terror, ao deslocamento, à infelicidade ou à morte de um ser animado; todo ato de intromissão que tem por efeito voluntário ou involuntário o desapossamento de outro, o prejuízo ou a destruição de objetos inanimados" (p. 28).

Outra importante abordagem conceitual acerca da violência nos é dada por Galtung (1995). Segundo este autor, a violência se faz presente em processos que habitualmente a desconhecem, por que não somente limita a sua consideração aos fatos abruptos e excessivos, senão a condições socioestruturais que se manifestam na série de ameaças evitáveis contra a satisfação das necessidades humanas básicas. A violência, nesse sentido, consiste na diminuição do nível real de satisfação das necessidades dos sujeitos por baixo do que seria potencialmente possível. Nas palavras do próprio Galtung (1995):

A violência está presente quando os seres humanos se vêem influenciados de tal maneira que suas realizações efetivas, somáticas e mentais, estão abaixo de suas realizações potenciais, de modo que quando o potencial é maior que o efetivo, e isso é evitável, existe violência (p. 314-315).

Num nível ontológico de análise, não há como evitar falarmos que a violência sempre alude a um vínculo de poder, para possibilitar a imposição da vontade, desejo ou projeto de um ator sobre outro, não se limitando a violência ao uso da força física, mas também se estendendo à possibilidade de ser usada para fins de ameaça ou intimidação psicológica (BOBBIO, 2010, p. 933). A violência nos remete à dinâmica das relações sociais, pois a presença de um "outro" nos distingue e diferencia como sujeito. Mais além dos acordos e da harmonia que podemos reconhecer nas interações sociais que permitem sustentar as sociedades, presenciamos as tensões pelas diferenças entre sujeitos e pelo acesso a algumas posições de maior poder.

Num mundo altamente complexo e desconcertante como o em que vivemos hoje, no qual as zonas anômicas se multiplicam, os sujeitos cada vez mais atuam segundo seus interesses mais particulares e egoístas, e nele a sexualidade é uma das esferas em que uma multiplicidade de valores atua intensamente na geração do agir humano, quando há largas justificativas para todo tipo de conduta exercida privada ou publicamente, e a imposição do desejo e o prazer de adultos sobre crianças, de homens sobre mulheres, de heterossexuais sobre homossexuais, evidencia-se numa magnitude e visibilidade que alcançaram os fatos de violência sexual e de gênero.

Os modos como reagem os indivíduos diante dos atos de violência respondem às condições em que se constituem como tais e às representações/interpretações que fazem do fenômeno; quer dizer, segundo as formas de incorporação dos princípios e elementos que orientam/determinam suas práticas. Por isso, nos encontramos com uma diversidade de sujeitos reagindo de maneiras diferentes diante de fatos semelhantes. Diante disso, para analisar as razões pelas quais sujeitos individualizados e/ou grupos envolvem-se em processos de violência, colocam-se algumas alternativas de aproximação investigativa, mas uma que tem assumido, 
historicamente, uma importância destacada é a que enfatiza um tensionamento entre distintas tradições de pensamento construídas nas ciências sociais e na filosofia política. Referimo-nos aos embates entre subjetivistas-individualistas e objetivistas-coletivistas.

\subsection{0 embate objetivismo x subjetivismo e suas repercussões na representação das tipologias da violência}

Destacar o caráter ativo, reflexivo, da conduta humana e da ação social, ou, em sentido diverso, entender ser o comportamento humano um resultado de forças que os atores não controlam nem compreendem, são os dois pontos fulcrais de compreensão sobre os quais se armam as tradições subjetivistas e objetivistas no âmbito das ciências sociais e da filosofia política. Esse embate e as possibilidades hermenêuticas dele emergentes são incontornáveis para um bom entendimento acerca dos principais aspectos ôntico-ontológicos do fenômeno da violência. A ocorrência desse embate varia de intensidade nas diferentes ciências sociais, havendo algumas em que uma tradição é predominante, por exemplo na psicologia, com uma hegemonia da tradição subjetivista, ou, em sentido contrário, na antropologia, na qual prevalece o objetivismo. Há, também, regionalidades científicas em que a oposição entre essas tradições guarda um maior equilíbrio, sem um esmagador predomínio de uma em detrimento da outra, como é o caso da sociologia.

A opção teórica aqui esboçada tem como ponto de partida o fato de que, como bem já observara Bobbio (1999, p. 45), toda a história do pensamento político, ao que por ora se agrega também o pensamento jurídico, está dominada por uma grande dicotomia: organicismo (holismo) e individualismo (atomismo). Mesmo que esse movimento dicotômico não seja retilíneo e permanente, havendo até mesmo momentos históricos em que ele encontra lapsos de arrefecimento, é possível afirmar que, em encruzilhadas marcantes da vida social e institucional do ocidente, ela se fez notar de forma marcante.

Essa dicotomia holismo/atomismo compõe um conflito de tradições de pesquisa intelectual com reflexos nas mais variadas construções culturais ocidentais. Cada uma delas foi e continua sendo parte da elaboração de um modo de vida social e moral do qual a própria pesquisa intelectual foi e ainda é parte integrante. Em cada uma delas, as formas dessa vida permanecem incorporadas às instituições sociais, econômicas, políticas e jurídicas. Essas tradições, utilizando o pensamento de Maclntyre, diferem entre si muito mais do que suas concepções conflitantes de racionalidade prática e justiça: elas diferem nos catálogos de virtudes, nas concepções do eu e nas cosmologias metafísicas; diferem também no modo como, em cada uma delas, se chegou às concepções de racionalidade prática e justiça (1991, p. 375-376).

A partir de investigações, debates e conflitos realizados desde tradições de pesquisa que privilegiam ou a subjetividade ou a objetividade socialmente materializadas e historicamente contingentes, as disputas referentes à racionalidade prática e à justiça são propostas, modificadas, abandonadas ou substituídas. Essas tradições de pesquisa, nesse sentido, surgem como base de justificação racional e de crítica de concepções de racionalidade prática e justiça.

Tais tradições diferem radicalmente em relação a uma gama numerosa de assuntos, que se constituem como categorias fundamentais de cada uma delas. Divergem, por exemplo, atomistas e holistas, visceralmente quanto às questões que dizem respeito ao grau de permissividade para a intervenção estatal na sociedade civil quanto à propriedade, às matérias tributárias, ao direito econômico, ou, dentro do foco deste trabalho, quanto às concepções de violência e, por consequência, quanto às estratégias políticas e jurídicas a serem adotadas para o enfrentamento desse problema. Por outro lado, convergem harmoniosamente para a solução de outros problemas, pois não resta qualquer dúvida de que individualistas e coletivistas concordam que o homicídio e o estupro são condutas que merecem ser reprimidas mediante a imposição de sanções penais, ou, por outro lado, que alguns parâmetros mínimos de direitos sociais devem ser concretizados.

É importante destacar, dentro do foco da presente reflexão, que em termos de gênese da violência a divergência entre subjetivistas e objetivistas é bastante forte, pois, enquanto os primeiros entendem ser o principal elemento genético desse fenômeno a vontade individual dos agentes, os segundos compreendem o crime como resultante de fatores sociais que transcendem o indivíduo.

Nessas áreas, em que há questões ou assuntos comuns a mais de uma tradição, uma delas pode estruturar suas teses por meio de conceitos tais que impliquem necessariamente a falsidade das teses sustentadas por uma ou mais tradições, embora, ao mesmo tempo, não exista nenhum padrão comum, ou somente exista padrões insuficientes para que se possa julgar os pontos de vista adversários. Muitas vezes, considerações 
exigidas no interior da tradição atomista apenas podem ser ignoradas pelos que conduzem a pesquisa ou o debate na tradição holista, à custa de, segundo seus próprios padrões, excluir boas razões para crer ou descrer em algo, ou para agir de uma forma e não de outra. Inobstante, não raro acontece que, em outras áreas, o que é afirmado por objetivistas pode, aprioristicamente, não encontrar nenhuma equivalência entre subjetivistas, ou vice-versa. Esta última situação surge de forma bastante clara, por exemplo, em relação à concretização dos direitos fundamentais de natureza não individual dentro de uma estrutura normativa e institucional predominantemente especializada para a efetivação de direitos individuais. A forma de construção do direito liberal-individualista e, particularmente, de algumas de suas ramificações, faz com que surja uma série de obstáculos quase intransponíveis quando se pensa na efetivação de novas funções do Direito num projeto constitucional com vertente social-democrática, fundada, de forma inovadora, em direitos fundamentais com diferentes funcionalidades, pois estes têm uma gama de idiossincrasias que exige um outro modelo normativo, uma outra forma jurídica que se distancia, em vários pontos, da liberal-individualista.

A demonstração da permanência e atualidade das discussões e pesquisas realizadas contemporaneamente no universo das ciências sociais, tendo como pano de fundo o embate entre subjetivistas e objetivistas, e, especificamente, no âmbito do direito e das alternativas práticas de solução dos conflitos, justifica-se na medida em que, se, de fato, a violência é a resultante de uma decisão e de um comportamento meramente individual, sem maiores influências de fatores exógenos ao agente, e as soluções individualizadas, por exemplo, as medidas protetivas previstas em nossa legislação, parecem não ser uma má opção política, devendo sua (in)eficácia ser pensada em termos de gestão pública orçamentária, com um foco na relação custo-benefício para a administração, ou em termos de otimização de aspectos da aplicação e execução da lei, tanto em termos normativos quanto corporativos em relação às agências governamentais pelas quais são executadas as políticas públicas e as decisões judiciais. Em outro sentido, é possível trabalhar sobre a hipótese de que a violência é o corolário também de forças sistêmicas ou estruturais, que atuam objetivamente, separadamente ou em conjunto, com a vontade ou motivação individual, sendo, nesta perspectiva, a violência um fenômeno total ou parcialmente transcendente aos indivíduos e, portanto, as soluções devem ser pensadas também dessa maneira, mais em termos de políticas públicas de reposicionamento social dos agentes hipossuficientes à violência ou de redistribuição de bens sociais de forma a empoderá-los, suavizando, assim, os efeitos das assimetrias das relações de poder na geração dos processos de violência. Uma terceira via, que se constitui numa das orientações principais do presente trabalho, pode ser cunhada a partir da consideração das relevâncias dessas duas vertentes de pesquisa e pensamento, quando tanto a subjetividade e a reflexividade do agente quanto a objetividade estrutural de fatores externos, jogam um importante papel causal na gênese da violência, e, portanto, devem ser consideradas ponto de partida para a projeção de novas práticas de solução dos conflitos, em que gênero e sexualidade são apontados como importantes marcadores desses conflitos.

Esse embate, que tem se constituído numa das principais, senão na principal contenda de base nas ciências sociais e na filosofia política, está presente num paradoxo relativo à nossa própria concepção de violência. Como bem alerta Žižek (2014, p. 17), os sinais mais evidentes de violência que nos vêm à mente são atos de crime e terror, confrontos civis e conflitos internacionais. Segundo ele, todavia, devemos aprender a dar um passo para trás e a desembaraçar-nos do engodo fascinante dessa violência "subjetiva" diretamente visível, exercida por um agente claramente identificável. Precisamos ser capazes de perceber os contornos dos cenários que engendram essas explosões. O passo para trás nos permite identificar uma violência que subjaz aos nossos próprios esforços que visam a combater a violência e promover a tolerância.

A violência subjetiva, na visão de Žižek (2014, p. 17), é somente a parte mais visível de um triunvirato que inclui também dois outros tipos de violência, ambos objetivos. Em primeiro lugar, há uma violência "simbólica" encarnada na linguagem e em suas formas, naquilo que Heidegger chamaria a "nossa casa do ser". Essa violência não está em ação apenas nos casos evidentes - e largamente estudados - de provocação e de relações de dominação social que nossas formas de discurso habituais reproduzem: há uma forma ainda mais fundamental de violência que pertence à linguagem enquanto tal, à imposição de um certo universo de sentido, como ocorre, por exemplo, nos discursos fundamentalistas homofóbicos ou misóginos, nos quais se perpetuam as tentativas infundadas de naturalização de discursos de anormalidade dos gays e lésbicas, ou da condição de submissão biológica da mulher. Em segundo lugar, há aquilo a que se pode chamar violência "sistêmica", que consiste nas consequências muitas vezes catastróficas do funcionamento regular de nossos sistemas econômico e político. 
A questão fulcral que se coloca é que a possibilidade de percebermos esses distintos tipos de violência e o modo como as percebemos, tem sérias implicações nas institucionalizações e práticas políticas que elaboramos para enfrentá-las. As violências subjetiva e objetiva não podem ser percebidas do mesmo ponto de vista: a violência subjetiva é experimentada enquanto tal contra o pano de fundo de um grau zero de não violência. É notada como uma perturbação do estado de coisas "normal" e pacífico. A violência objetiva, contudo, é precisamente aquela inerente a esse estado "normal" de coisas. A violência objetiva é uma violência invisível, uma vez que é precisamente ela que sustenta a normalidade do nível zero contra a qual percebemos algo como subjetivamente violento. Assim, a violência sistêmica é, de certo modo, algo como a célebre "matéria escura" da física, a contrapartida de uma violência subjetiva (demasiado) visível. Pode ser invisível, mas é preciso levá-la em consideração se quisermos elucidar o que parecerá, de outra forma, explosões "irracionais" de violência subjetiva.

Essa dualidade subjetivo-objetivo, e também o seu caráter velado, escondido, dissimulado na maioria das vezes, do fenômeno da violência, aparece também numa abordagem classificatória de Galtung (1995), a qual guarda uma proximidade muito grande com a análise de Žižek (2014). Na dinâmica da vida social, este autor distingue três formas de violência: a direta, a estrutural e a cultural - correspondentes à violência subjetiva, sistêmica e simbólica na classificação žižekiana, respectivamente. A primeira, a violência direta, é a visível (física ou verbal, por todos perceptível), e as outras duas, violência estrutural e violência cultural, tornam-se invisíveis ao olho do não especialista. A violência estrutural é definida como a soma total de todos os choques incrustrados nas estruturas sociais e mundiais, e remete a situações de exploração, discriminação e marginalização. Já a violência cultural está constituída pelos arrazoamentos, atitudes, ideias que promovem, legitimam e justificam a violência em suas formas direta ou estrutural (GALTUNG, 1995, p. 315-316). As três formas estão relacionadas e condicionadas, pois a direta é produto dos efeitos das duas invisíveis - estrutural e cultural -, mas estas, por sua vez, são solidárias entre si, gerando um circuito de retroalimentação que requer uma profunda reflexão para ser desarticulada. Nos termos de Crettiez (2009), estas duas últimas formas constituem o que denomina "determinantes coletivas da violência - pontualmente referindo-se à marginalidade política, à frustração econômica e à valorização social da violência -, condições elementares - mas nem sempre reconhecidas pelos sujeitos envolvidos nelas - que tornam possíveis que um sujeito participe em atos de violência (p. 12-13).

Philippe Bourgois (2001), buscando uma aproximação num nível mais fenomenológico, elabora uma tipologia de violência articulando aportes de diversos autores, como Galtung, Bourdieu e Scheper-Hughes, estabelecendo quatro formas que podem se combinar e não se excluírem: a violência política, a violência estrutural, a violência simbólica e a violência cotidiana ou de todos os dias. A violência estrutural segue a mesma definição de Galtung (1995). Sua diferenciação está no âmbito da violência política e da simbólica. A primeira é a que se exerce direta e decididamente em nome de uma ideologia política, ou de um Estado tal como a repressão física ante o dissenso executada pelo exército ou pela polícia, ou a luta armada popular contra um regime repressivo. Já a simbólica relaciona-se com o "como" opera a dominação desde um nível íntimo, por meio do autorreconhecimento das estruturas de poder por parte do dominado que coadjuva sua própria opressão, dado que percebe e julga a ordem social por intermédio das categorias dos dominantes que naturalizam a opressão.

Crettiez (2009, p. 17-18) também propõe uma diferenciação entre os tipos de violência, distinguindo basicamente entre a visível e a invisível, e com esta distinção analisa as variadas formas de expressão da violência. Entre as primeiras, destaca a violência física, que se expressa segundo diferentes circunstâncias e pode ser analisada como violência contingente à ordem social ordinária, ou violência inerente à ação, ao sistema político ou violência instrumental. Entre as invisíveis se detém na estrutural e na simbólica, tomando também como referentes Galtung e Bourdieu.

\section{GÊNERO E VIOLÊNCIA COMO CRITÉRIOS DE MARCAÇÃO DOS FENÔMENOS DE VIOLÊNCIA}

Movendo-nos por essas distintas classificações que reconhecem, por variadas perspectivas, o fenômeno da violência, as diferenças de gênero e sexualidade apresentam-se como uma das justificativas mais eficazes para o exercício da violência. A violência de gênero destaca-se sob dois panoramas: uma, restrita às mulheres; 
outra, mais ampla, que inclui diferentes gêneros e manifestações de sexualidade. A primeira considera violência de gênero, segundo Espinar Ruiz: "la violencia ejercida contra una mujer por parte de su pareja o ex-pareja, es una violencia directa con claras dimensiones de género en la medida en que interrelaciona con unas formas concretas de violencia estructural (relaciones patriarcales) y cultural (ideologias machistas)" (2004, p. 78). Na segunda acepção temos como violência de gênero "una forma de violencia que se fundamenta en unas relaciones de dominación por razón de género y en unas concretas definiciones de género; es decir, también en una dominación en el plano simbólico-cultural (ESPINAR RUIZ; MATEO PÉREZ, 2007, p. 198).

No âmbito da comunidade política internacional, segundo o Informe Mundial sobre Violência e Saúde, a violência sexual é definida como "todo ato sexual, a tentativa de consumar um ato sexual, os comentários e insinuações sexuais não desejados, ou as ações para comercializar ou utilizar de qualquer outro modo a sexualidade de uma pessoa mediante coação por outra pessoa, independentemente da relação desta com a vítima, em qualquer âmbito, incluídos o lar e o lugar de trabalho" (OMS, 1993). Este conceito encerra, especialmente por sua origem, uma definição bastante restringida às mulheres (ESPINAR RUIZ, 2004, p. 93).

Outros autores, como Chejter (2007), colocam que a violência de gênero é um conceito amplo que inclui violações sexuais, acosso sexual, prostituição, abusos sexuais e feminicídios, tanto no âmbito público quanto privado. Adverte que não há uma forma somente de molestar; coexistem ações que podem ser: violência física, emocional, psicológica, sexual, econômica ou patrimonial. Ao referir-se à violência de gênero, assinala que esta se articula também com outras formas de violência: a étnica, de classe, econômica, institucional, cultural, religiosa, entre grupos de conflitos etc. (ESPINAR RUIZ, 1994, p. 93).

Outras definições integram, em conceitos mais amplos e densos, expressões fenomenológicas diversas, aparentemente desconexas, que dão conta de processos mais complexos e sutis, como a violência simbólica e a violência moral. A violência simbólica é uma decorrência do exercício do poder simbólico que, segundo Bourdieu (1998b, p. 11), enquanto instrumento estruturado e estruturante de comunicação e conhecimento, cumpre a sua função política de instrumento de imposição ou de legitimação da dominação, que contribui para assegurar a dominação de uma classe por outra (violência simbólica). Nesse processo, de acordo com Bourdieu,

As diferentes classes e frações de classes estão envolvidas numa luta propriamente simbólica para imporem a definição do mundo social mais conforme aos seus interesses, e imporem o campo de tomadas de posições ideológicas reproduzindo em forma transfigurada o campo das posições sociais (1998b, p. 11).

Já violência moral, nos termos propostos por Segato (2003), relaciona-se ao conjunto de mecanismos legitimados para garantir a manutenção dos status relativos entre os termos de gênero. Estes mecanismos de preservação de sistemas de status operam também no controle da permanência de hierarquias em outras ordens, como o racial, o étnico, o de classe, o regional e o nacional (SEGATO, 2003, p. 107). Mais adiante, a mesma autora afirma que

La violencia moral es el más eficiente de los mecanismos de control social y reproducción de las desigualdades. La coacción de orden psicológico se constituye en el horizonte constante de las escenas cotidianas de sociabilidad y es la principal forma de control de las categorías sociales subordinadas. En el universo de las relaciones de género, la violencia psicológica es la forma de violencia más maquinal, rutinaria e irreflexiva y, sin embargo, constituyen el método más eficiente de subordinación e intimidación (p. 114).

Segato (2003) ainda destaca que a eficácia da violência moral na reprodução das desigualdades radica-se em três aspectos que a constituem: 1 ) sua disseminação massiva na sociedade, sua naturalização como parte da normalidade; 2 ) seu arraigo em valores morais religiosos e familiares que permitem sua justificação; e 3) a falta de nomes ou outras formas de designação e identificação das condutas que torna impossível assinalá-las ou tipificá-las e, portanto, dificultam a denúncia e impedem às vítimas defenderem-se (p. 119).

A importância desse nosso percurso por distintas taxinomias acerca da violência e, mais especificamente, da violência de gênero, reside no fato de que a visibilidade de processos submersos ou inconscientes de violência constitui-se numa condição primordial para processos públicos de tomadas de decisão políticas e jurídicas eficazes no enfrentamento desse fenômeno. A visibilidade ou invisibilidade dos processos de violência depende do habitus do observador. A possibilidade de reconhecer como expressões de violência de gênero e de violência sexual certas práticas sociais, nos remete, antes, ao "como" e ao "desde onde" interpretamos 
essas práticas, do que propriamente a fatos empíricos. Este percurso por categorias descritivas do fenômeno da violência nos possibilita tomar consciência da variabilidade dos modos pelos quais pode expressar-se essa vontade e impor-se sobre os outros, pois a violência é um fenômeno de múltiplas caras e fundamentos nas distintas realidades históricas e sociais. Para decifrar sua complexidade, não há remédio melhor do que segmentá-la em modalidades significativas (MARTíN FERRANDIZ; FEIXA PAMPOLS, 2004, p. 159).

\section{A TIPOLOGIA DA VIOLÊNCIA NA POLÍTICA NACIONAL DE ENFRENTAMENTO À VIOLÊNCIA CONTRA AS MULHERES NO BRASIL}

No documento denominado Política Nacional de Enfrentamento à Violência contra as Mulheres no Brasil, elaborado pela Secretaria Nacional de Enfrentamento à Violência contra as Mulheres, vinculada à Presidência da República, a partir do Plano Nacional de Políticas para as Mulheres (PNPM), criado com base na I Conferência Nacional de Políticas para as Mulheres, realizada em 2004 pela Secretaria de Políticas para as Mulheres (SPM) e pelo Conselho Nacional dos Direitos da Mulher (CNDM), uma série de conceitos e diretrizes foram elaborados, dentre eles um conceito institucionalizado de violência contra a mulher. Diz o documento que

O conceito de violência contra as mulheres, adotado pela Política Nacional, fundamenta-se na definição da Convenção de Belém do Pará (1994), segundo a qual a violência contra a mulher constitui "qualquer ação ou conduta, baseada no gênero, que cause morte, dano ou sofrimento físico, sexual ou psicológico à mulher, tanto no âmbito público como no privado" (Art. 1²) (BRASIL, 2011, p. 19).

A definição é, portanto, ampla e abarca diferentes formas de violência contra as mulheres, tais como: a) a violência doméstica ou em qualquer outra relação interpessoal, em que o agressor conviva ou tenha convivido no mesmo domicílio que a mulher, compreendendo, entre outras, as violências física, psicológica, sexual, moral e patrimonial (Lei no 11.340/2006); b) a violência ocorrida na comunidade e que seja perpetrada por qualquer pessoa, e que compreende, entre outros, violação, abuso sexual, tortura, tráfico de mulheres, prostituição forçada, sequestro e assédio sexual no lugar de trabalho, bem como em instituições educacionais, estabelecimentos de saúde ou qualquer outro lugar; c) a violência perpetrada ou tolerada pelo Estado ou seus agentes, onde quer que ocorra (violência institucional).

Essa Política Nacional reconhece uma considerável gama de manifestações de violência contra a mulher, expressa na seguinte tipologia (BRASIL, 2011, p. 22-24):

a) Violência doméstica, entendida como qualquer ação ou omissão baseada no gênero que cause à mulher morte, lesão, sofrimento físico, sexual ou psicológico e dano moral ou patrimonial no âmbito da unidade doméstica, da família ou em qualquer relação íntima de afeto, na qual o agressor conviva ou tenha convivido com a ofendida, independentemente de coabitação (Lei no 11.340/2006). A violência doméstica contra a mulher subdivide-se em: violência física, violência psicológica, violência sexual, violência patrimonial e violência moral. 0 parágrafo único do artigo 5o da Lei Maria da Penha dá visibilidade à violência doméstica e familiar contra as mulheres lésbicas, ao afirmar que "as relações pessoais enunciadas neste artigo independem de orientação sexual".

b) Violência sexual - considerada como a ação que obriga uma pessoa a manter contato sexual, físico ou verbal, ou participar de outras relações sexuais com uso da força, intimidação, coerção, chantagem, suborno, manipulação, ameaça ou qualquer outro mecanismo que anule o limite da vontade pessoal.

c) Violência física - abarcando qualquer conduta que ofenda a integridade ou saúde corporal da mulher.

d) Violência psicológica - considerada como a conduta que cause dano emocional e diminuição da autoestima da mulher ou que the prejudique e perturbe o pleno desenvolvimento, ou que vise a degradar ou controlar suas ações, comportamentos, crenças e decisões, mediante ameaça, constrangimento, humilhação, manipulação, isolamento, vigilância constante, perseguição contumaz, insulto, chantagem, ridicularização, exploração e limitação do direito de ir e vir ou qualquer outro meio que lhe cause prejuízo à saúde psicológica e à autodeterminação. 
e) Violência patrimonial - a qual inclui qualquer conduta que configure retenção, subtração, destruição parcial ou total de seus objetos, instrumentos de trabalho, documentos pessoais, bens, valores e direitos ou recursos econômicos, incluindo os destinados a satisfazer suas necessidades.

f) Violência moral - entendida como qualquer conduta que configure calúnia, difamação ou injúria.

g) Violência institucional - aquela praticada, por ação e/ou omissão nas instituições prestadoras de serviços públicos. Mulheres em situação de violência são, por vezes, "revitimizadas" nos serviços quando: são julgadas; não têm sua autonomia respeitada; são forçadas a contar a história de violência inúmeras vezes; são discriminadas em razão de questões de raça/etnia, de classe e geracionais. Outra forma de violência institucional que merece destaque é a violência sofrida pelas mulheres em situação de prisão, que são privadas de seus direitos humanos, em especial de seus direitos sexuais e reprodutivos.

h) Tráfico de mulheres - cujo conceito adotado pela Secretaria de Políticas para as Mulheres da Presidência da República do Brasil (SPM/PR) baseia-se em uma abordagem focada na perspectiva dos direitos humanos das muIheres e no Protocolo de Palermo, em que há três elementos centrais: 1. movimento de pessoas, seja dentro do território nacional ou entre fronteiras; 2 . uso de engano ou coerção, incluindo o uso ou ameaça da força ou abuso de autoridade ou situação de vulnerabilidade; e, 3. a finalidade de exploração (exploração sexual; trabalho ou serviços forçados, incluindo o doméstico; escravatura ou práticas similares à escravatura; servidão; remoção de órgãos; casamento servil).

i) Exploração sexual de mulheres - com previsão no Código Penal Brasileiro em seu Capítulo V - do Lenocínio e do Tráfico de Pessoa para fim de Prostituição ou outra forma de Exploração Sexual -, cujo artigo 227 traz que exploração sexual "é induzir alguém a satisfazer a lascívia de outrem", e o artigo 228 dispõe que é "induzir ou atrair alguém à prostituição ou outra forma de exploração sexual, facilitá-la, impedir ou dificultar que alguém a abandone".

j) Assédio sexual - considerado como a abordagem não desejada pelo outro com intenção sexual ou insistência inoportuna de alguém em posição privilegiada, que usa dessa vantagem para obter favores sexuais de subalternos ou dependentes. Para sua perfeita caracterização, o constrangimento deve ser causado por quem se prevaleça de sua condição de superior hierárquico ou ascendência, inerentes ao exercício de emprego, cargo ou função. $O$ assédio sexual é tipificado como crime (artigo 216-A, do Código Penal, com redação dada pela Lei no 10.224, de 15 de maio de 1991).

k) Cárcere privado, que, segundo o artigo 148 do Código Penal Brasileiro, configura-se quando uma pessoa é impedida de andar com liberdade e é mantida presa contra a vontade.

Ainda que a tipologia apresentada nesse documento seja extensa, ela cobre fundamentalmente as manifestações de violência subjetiva ou visível (ŽlŽEK, 2014), direta (GALTUNG, 1995) e cotidiana ou de todos os dias (BOURGOIS, 2001). Na tipologia positivada nesse documento não há qualquer menção às formas objetivas, invisíveis de violência praticadas contra as mulheres, de fundo estrutural, simbólico, cultural ou moral. A consequência disto é que o leque de medidas preventivas e repressivas de combate à violência contra a mulher, proposto no plano contido na Política Nacional de Enfrentamento à Violência contra as Mulheres, praticamente restringe-se a soluções voltadas às vítimas ou aos agressores de modo individualizado. Nos objetivos e nas ações e prioridades dessa política pública, ainda que haja menção no objetivo geral de "Enfrentar todas as formas de violência contra as mulheres a partir de uma perspectiva de gênero e de uma visão integral deste fenômeno" (BRASIL, 2011, p. 35) - destaque-se aqui a pretensão de enfrentar o problema desde uma visão integral do fenômeno -, o que se vislumbra, a partir da tipologia antes mencionada, é uma visão parcial, marcada por uma percepção deficiente da violência contra as mulheres apenas em sua faceta subjetiva, direta e cotidiana, deixando praticamente de lado as causas estruturais, simbólicas e culturais, que são as mais profundas e invisíveis, e cujo enfrentamento reclama estratégias e políticas públicas muito mais complexas, totalmente distintas das utilizadas para o tratamento da violência direta e visível.

Essa fixação da Política Nacional de Enfrentamento à Violência contra as Mulheres no aspecto subjetivo, direto e visível do fenômeno, revela uma enorme falha na monitoração reflexiva que tem sido feita em relação a esse universo fenomênico e, por consequência, na racionalização pretendida de nossas políticas públicas voltadas à prevenção e ao combate desse tipo de violência. Dados do Ligue 180 Central de Atendimento à Mulher, serviço criado e mantido pela Secretaria Especial de Políticas para as Mulheres, órgão vinculado ao Ministério da Justiça e Cidadania, revelam uma sensível ineficácia de nossas políticas de prevenção e repressão da violência contra a mulher, pois o aumento da violência de gênero em nosso país traduz-se numa curva crescente ano após ano (BRASIL, 2016b). Desde sua criação em 2005, o serviço já registrou 5.378 .774 atendimentos. Os dados mostram que, somente no 1 으 semestre de 2016, a Central realizou 555.634 atendimentos, 
o que, em média, contabiliza 92.605 atendimentos/mês e 3.052 atendimentos/dia. Essa quantidade foi $52 \%$ superior ao número de atendimentos realizados no 1 o semestre de 2015 (364.627). Do total de atendimentos do 1 o semestre de 2016, 12,23\% (67.962) corresponderam a relatos de violência. Dentre os relatos, $51,06 \%$ corresponderam à violência física; $31,10 \%$ violência psicológica; $6,51 \%$ violência moral; $4,86 \%$ cárcere privado; 4,30\% violência sexual; $1,93 \%$ violência patrimonial; e $0,24 \%$ tráfico de pessoas.

Em comparação com o mesmo período de 2015, a Central de Atendimento à Mulher constatou que, no tocante aos relatos de violência, houve um aumento de $142 \%$ nos registros de cárcere privado, com a média de 18 registros/dia e de $147 \%$ nos casos de estupro, com média de 13 relatos/dia.

No 1ㅇ semestre de 2016 foi notado o aumento de 133\% nos relatos relacionados à violência doméstica e familiar, comparando-se com o mesmo período do ano passado. Além disso, do total de informações prestadas (299.743), 25\% (76.633) referiram-se à Lei Maria da Penha e à violência doméstica e familiar.

Outro dado relevante e alarmante refere-se aos feminicídios praticados no Brasil. De acordo com o Mapa da Violência (WAISELFIZ, 2015), dos 4.762 homicídios de mulheres registrados em 2013, 50,3\% foram cometidos por familiares, sendo a maioria desses crimes $(33,2 \%)$ executados por parceiros ou ex-parceiros. Isso significa que a cada sete feminicídios, quatro foram praticados por pessoas que tiveram ou tinham relações íntimas de afeto com a mulher. A estimativa feita nesse relatório investigativo, com base em dados de 2013 do Ministério da Saúde, alerta para o fato de ser a violência doméstica e familiar a principal forma de violência letal praticada contra as mulheres no Brasil. O Mapa da Violência 2015 (WAISELFIZ, 2015) também mostra que o número de mortes violentas de mulheres negras aumentou 54\% em 10 anos, passando de 1.864, em 2003, para 2.875, em 2013. No mesmo período, a quantidade anual de homicídios de mulheres brancas diminuiu $9,8 \%$, caindo de 1.747, em 2003, para 1.576, em 2013.

Ainda que a Lei Maria da Penha tenha influenciado um pouco na diminuição dos feminicídios - a Pesquisa Avaliando a Efetividade da Lei Maria da Penha, realizada pelo Ipea (BRASIL, 2015b), mostrou que a Lei no 11.340/2004 fez diminuir em cerca de $10 \%$ a taxa de homicídios contra mulheres praticados dentro das residências das vítimas -, não teve a eficácia suficiente para diminuir drasticamente o problema, que a cada ano tem aumentado seus números absolutos.

Essa correspondência entre uma percepção subjetiva, direta, visível da violência e a adoção de medidas que tendem a ser aplicadas ao universo individualizado da vítima ou do agressor, encontra uma similaridade com as nossas práticas penais. A hegemonia subjetivista, tanto no plano teórico quanto no prático, tem levado a uma deficiente racionalização de nosso sistema penal e de nossas práticas penais, que se desvela, contemporaneamente, de forma bastante clara, quando comparamos as curvas de crescimento de nossa população carcerária, revelando a faceta mais escancarada de nossas práticas penais, com os números da violência em nosso país que se superam ano após ano, censo após censo. Os 61.283 homicídios cometidos no Brasil no ano de 2016, concomitantemente ao atingimento da cifra de 726.712 presos no mesmo ano, são a prova irrefutável da total irracionalidade de nossas políticas públicas de enfrentamento do fenômeno da criminalidade. Há uma relação diretamente proporcional entre o crescimento da criminalidade e o aumento de encarcerados, o que demonstra, estatisticamente, a falência total de nossas práticas penais e a debilidade dos discursos preventivos de justificação do sistema.

Um dos grandes desafios que se coloca diante de um quadro conjuntural em que a violência, em suas múltiplas facetas, não tem cedido terreno, mas, muito pelo contrário, tem ganhado mais e mais território em nossa sociedade, é mudarmos nosso lugar de observação e a nossa própria visão sobre o fenômeno da violência, abandonando a exclusividade das lentes subjetivistas/individualistas e migrando para uma perspectiva que, não abandonando nossa percepção da violência direta, visível, suas causas e motivos, também acolha uma compreensão acerca das condições objetivas (estruturais, sistêmicas) determinantes das múltiplas tipologias da violência.

\section{CONSIDERAÇÕES FINAIS}

\section{O grande desafio em termos de violência de gênero: o enfrentamento do poder simbólico e da coerção} das estruturas sociais e suas condições determinantes da violência 
Há um sistema mundial de comunicação-dominação cujo conteúdo de suas comunicações são fundamentalmente patriarcais e heterossexuais. Notadamente, por uma vontade de poder incontrolável, homens adultos, via de regra heterossexuais, dominaram a sociedade planetária, ocupando os espaços de poder e submetendo todas as demais parcelas de seres humanos a vulnerabilidades e violações insuportáveis. Tais estados de dominação desequilibraram de tal forma a configuração de convivência entre os seres humanos, que, ao longo do século passado, as reações de mulheres, homossexuais e outros sacrificados por esses dominadores, foram circunstancialmente inevitáveis.

Há um inconsciente, agora já nem tão inconsciente assim, patriarcal, masculino e heterossexual, que funciona mediante um sistema de comunicações praticamente silencioso, mas avassaladoramente eficaz na estruturação e dinâmica dos processos de dominação das mulheres pelos homens e de homossexuais por heterossexuais. Ainda que praticamente estejam erradicadas das democracias ocidentais contemporâneas quaisquer espécies de dispositivos que permitam a legitimação de ações discriminatórias explícitas contra as mulheres, e ainda que haja, na superfície, a configuração de um cenário, pelos menos no plano normativo, de uma total igualdade de gênero, essas perspectivas, se não aprofundadas, revelam um olhar absolutamente ingênuo, pois as injustiças e desigualdades permanecem inescrupulosamente presentes em nossas sociedades ocidentais ditas democráticas. Em outras palavras, embora tenhamos evoluído em termos de positivação normativa de uma quantidade significativa de dispositivos contramajoritários voltados à proteção dos dominados e violentados, as comunicações do sistema patriarcal não foram interrompidas, continuando a atuar fortemente nos processos de dominação e violência.

Não há qualquer dúvida em afirmarmos que há placas tectônicas poderosíssimas e silenciosas, cujo movimento é determinado pela diferenciação de gênero. Ainda que na superfície não percebamos, pelo menos no ocidente, a ocorrência de terremotos discriminatórios de alta magnitude sismológica, permanece um lento movimento de continentes territoriais, determinados por essas placas patriarcais e heterossexuais que definem a importância dos papéis e posições segundo preferências de gênero/sexualidade a partir de uma visão de mundo masculina. Há um inconsciente patriarcal diluído numa normalidade supostamente igualitária, como bem nos mostra Mackinnon (1987) ao afirmar que:

Virtualmente toda qualidade que distingue os homens das mulheres já é afirmativamente compensada nesta sociedade. A fisiologia dos homens define a maioria dos esportes, suas necessidades definem a cobertura dos seguros de automóveis e de saúde, suas biografias projetadas para o social definem as expectativas de local de trabalho e padrões bem-sucedidos de carreira, suas perspectivas e interesses definem a qualidade no trabalho acadêmico, suas expectativas e obsessões definem o mérito, sua objetificação da vida define a arte, seu serviço militar define a cidadania, sua presença define a família, sua incapacidade de se darem bem uns com os outros - suas guerras e governos - definem a história, sua imagem define Deus e seus órgãos genitais definem o sexo. Para cada uma das diferenças ante a mulher, está em vigor o que equivale a um plano de ação afirmativa, conhecido, de outra maneira, como a estrutura e os valores da sociedade americana (1987, p. 36).

Disso, o que se percebe, epidermicamente, é uma neutralidade quanto ao gênero, no sentido de que as mulheres estão numa posição de igualdade em relação aos homens, ou os homossexuais em relação aos heterossexuais, não estando excluídos em suas buscas por bens sociais valiosos. Adensando a análise, entretanto, é possível visualizar e entender que o que está sendo buscado de maneira neutra quanto ao gênero é totalmente parcializado, direcionado, se tomarmos em conta a preponderância profunda, silenciosa, inconsciente e eficaz dos interesses e valores patriarcais. Fazendo nossas as palavras de Kymlicka (2006), "as mulheres estão em desvantagem não porque os chauvinistas favorecem os homens arbitrariamente na concessão de trabalhos, mas porque a sociedade inteira favorece sistematicamente os homens ao definir trabaIhos, méritos, etc." (p. 310).

A consequência disso é um sistema simbólico de identificações culturais no qual a masculinidade é associada à obtenção de renda e a feminilidade é definida em virtude de serviços sexuais e domésticos para os homens e para a criação de filhos. Essas situações de dominação não podem ser compreendidas em toda a sua espessura desde aproximações subjetivistas. Elas são amplamente objetivas, pois os homens, como grupo, exercem um fortíssimo controle sobre as possibilidades existenciais das mulheres. 
Nesse quadro de dominação, vamos encontrar na posição de dominadores tanto homens brancos europeus quanto homens negros africanos; vamos presenciar não somente a dominação patriarcal comum a países árabes, mas também no extremo oriente; presenciaremos, no mundo contemporâneo, estados de dominação patriarcal com justificação religiosa não apenas por cristãos americanos e europeus, mas também por muçulmanos e hindus da metade oriental do planeta.

A gravidade dos estados de dominação impostos pelas comunicações patriarcais-heterossexuais é tão significativa que ainda hoje testemunhamos as mulheres em posição de inferioridade social, econômica e política em praticamente todos os países do mundo. O peso da subjugação masculina é tão grande, que mulheres que mantenham relações sexuais fora do contrato matrimonial, ou mesmo após a morte do marido, são condenadas judicialmente por adultério e mortas por apedrejamento em países em que há vinculação entre a religião e o Estado, notadamente islâmicos ortodoxos. A opressão, nesse aspecto, ainda é tão intensa que a homossexualidade permanece sendo considerada crime em um razoável número de países, sendo previstas penas até mesmo de morte.

Assim sendo, cabe a nós, juristas, o imenso desafio de achar alternativas fora de nossas zonas normativas de conforto, com base simplesmente em mecanismos repressivos dirigidos aos autores dos eventos de violências. O princípio da igualdade ainda não é suficiente para criar condições normativas de equalização das condições fáticas envolvendo os distintos grupos com buscas identitárias a partir do gênero e da sexualidade, apesar de já ter criado um bom suporte principiológico-normativo para avanços civilizatórios nas relações de gênero. Cabe-nos, antes de mais nada, repensarmos as bases epistemológicas e conceituais desde as quais temos interpretado o fenômeno da violência, e em especial a violência de gênero, deslocando o foco de uma observação prioritariamente individualista, para que possamos, com a agregação de uma perspectiva objetivista - simbólica e sistêmica -, conseguirmos apreender melhor a complexidade das ocorrências da violência de gênero e, com isso, elaborarmos tecnologias sociais mais eficazes.

\section{REFERÊNCIAS}

BENJAMIN, W. Para uma crítica da violência. In: BENJAMIN, W. Escritos sobre mito e linguagem. Tradução Ernani Chaves. Organização Jeanne Marie Gagnebin. São Paulo: Editora 34; Duas Cidades, 2011. p. 121-156.

BÍBLIA SAGRADA. Rio de Janeiro: Imprensa Bíblica Brasileira, 1988.

BOBBIO, Norberto. Dicionário de política. 13. ed. Brasília: UnB, 2010.

BOBBIO, Norberto. Liberalismo e democracia. São Paulo: Brasiliense, 1999.

BOURDIEU, Pierre. A dominação masculina. Rio de Janeiro: Bertrand Brasil, 1998a.

BOURDIEU, Pierre. O poder simbólico. Rio de Janeiro: Bertrand Brasil, 1998b.

BOURGOIS, Philippe. The power of violence in war and Peace Post-Cold War lessons from El Salvador. Etnography, São Francisco, University of California, v. 2, issue 1, p. 5-34, 2001.

BRASIL. Constituição da República Federativa do Brasil de 1988. 1988. Disponível em: http://www.planalto.gov.br/ccivil_03/ constituicao/constituicaocompilado.htm. Acesso em: 27 set. 2016.

BRASIL. Levantamento de Informações Penitenciárias (Infopen). Brasília: Ministério da Justiça, 2016 a.

BRASIL. Decreto-Lei n. 2848 de 07 de dezembro de 1940. Código Penal Brasileiro. Disponível em: http://www.planalto.gov.br/ ccivil_03/decreto-lei/Del2848compilado.htm. Acesso em: 27 set. 2016.

BRASIL. Lei n. 3071 de $1^{\circ}$ de janeiro de 1916. Código Civil Brasileiro. Disponível em: http://www.planalto.gov.br/ccivil_03/leis/ L3071.htm. Acesso em: 27 set. 2016.

BRASIL. Projeto de Lei 236/2012. Dispõe sobre a Reforma do Código Penal Brasileiro. Senado Federal. Disponível em: https:// www25.senado.leg.br/web/atividade/materias/-/materia/106404. Acesso em: 27 set. 2016.

BRASIL. Projeto de Lei 478/2007. Dispõe sobre o Estatuto do Nascituro e dá outras providências. Câmara dos Deputados. Disponível em: http://www.camara.gov.br/-proposicoesWeb/fichadetramitacao?idProposicao-=345103. Acesso em: 24 jul. 2016.

BRASIL. Projeto de Lei 618/2015. Acrescenta o art. 225-A ao Decreto-Lei no 2.848, de 7 de dezembro de 1940 - Código Penal, para prever causa de aumento de pena para o crime de estupro cometido por duas ou mais pessoas. 2015a. Disponível em: http://www25.senado.leg.br/web/atividade/materias/-/materia/123183. Acesso em: 27 set. 2016.

BRASIL. Ministério da Justiça e Cidadania. Secretaria Especial de Políticas para as Mulheres. Ligue 180 Central de Atendimento à Mulher. Balanço 1으 semestre de 2016. Brasília, 2016b. 
BRASIL. Ministério do Planejamento. Ipea. Avaliando a Efetividade da Lei Maria da Penha. Brasília, mar. 2015b. Disponível em: http://www.ipea.gov.br/portal/images/stories/PDFs/TDs/td_2048k.pdf. Acesso em: 19 fev. 2018.

BRASIL. Secretaria Nacional de Enfrentamento à Violência contra as Mulheres. Política Nacional de Enfrentamento à Violência contra as Mulheres. Brasília, 2011, p. 19.

CHEJTER, Silvia. Nudos críticos en las políticas públicas contra la violencia y las políticas de salud en Argentina. Violencia. Sexualidad. Reproducción. Tensiones políticas, éticas y jurídicas. Buenos Aires: Cecym, 2007.

CRETTIEZ, Xavier. Las Formas de la Violencia. Buenos Aires: Waldhuter Editores, 2009.

DELEUZE, Gilles. Conversações. São Paulo: Ed. 34, 1992.

ESPINAR RUIZ, Eva. Violencia de género y procesos de empobrecimento. 2004. Tese (Doutoral). Universidad de Alicante. Departamento de Sociología II, Alicante, 2004.

ESPINAR RUIZ, Eva; MATEO PÉREZ, Miguel Angel. Violencia de género: reflexiones conceptuales y derivaciones práticas. Papers. Revista de Sociología, Universidad Autónoma de Barcelona, n. 86, p. 189-201, 2007.

FREUD, Sigmund. O Eu e o Id, "Autobiografia" e outros Textos. São Paulo: Companhia das Letras, 2011.

GALEANO, Eduardo. Espelhos. Uma história quase universal. Porto Alegre: LPM, 2008.

GALTUNG, Johan. Investigaciones Teóricas. Sociedad y Cultura Contemporáneas. Madrid: Tecnos, 1995.

HEIDEGGER, Martin. A caminho da linguagem. Trad. Márcia Sá Cavalcante Schuback. Petrópolis, RJ: Vozes; Bragança Paulista, SP: Editora Universitária São Francisco, 2003.

HERITIER, Françoise. Masculin/féminin. La pensée de ladifférence. Paris: Odile Jacob, 1996.

KIMLICKA, Will. Filosofia Política Contemporânea. São Paulo: Martins Fontes, 2006.

MACINTYRE, Alasdair. Justiça de quem? Qual racionalidade? 2. ed. São Paulo: Loyola, 1991.

MACKINNON, Catherine. Feminism Unmodified. Cambridge: Harvard University Press, 1987.

MARTÍN FERRANDIZ, Francisco; FEIXA PAMPOLS, Carles. Una mirada antropológica sobre las violencias. Alteridades, México, D.F.: Universidad Autónoma Metropolitana, v. 14, enero/julio 2004, p. 159-174.

MOORE, Henrietta. Antropología y Feminismo. 2. ed. Madrid: Ed. Cátedra Universidad de Valencia e Instituto de la Mujer, 1996. OMS. Organização Mundial da Saúde. Informe mundial sobre a violência e a saúde. Declaração contra a violência dirigida às mulheres. Washington: OMS, 1993.

ROSALDO, Michelle. Mujer, Cultura y Sociedad: una visión teórica. In: MARTIN, M. K.; VOORHIES, B. (org.). La Mujer: un Enfoque Antropológico. Barcelona: Anagrama, 1978.

SEGATO, Rita. Las Estructuras Elementales de la Violencia. Buenos Aires: Paidós, 2003.

WAISELFIZ, Julio Jacobo. Mapa da Violência 2015. Homicídio de Mulheres no Brasil. Brasília: Flacso, 2015.

ŽlŽEK, Slavoj. Violência. São Paulo: Boitempo, 2014. 